
of years, such as forty or fifty, and this view is confirmed by actual experience. For in 1908, in my early years in India, I published an admittedly imperfect formula for predicting the monsoon based on about 34 years of data ; and its reliability can

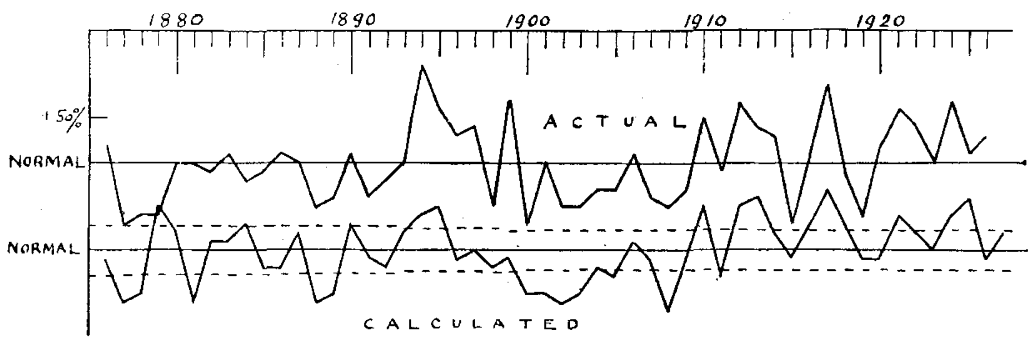

FIG. 3.-Forecast on Dec. 1 of Ceara rainfall, January-June. based on close relations over an adequate number

of 0.76 instead of 0.58 . Also, there is no reason whatever for thinking that finality has been reached; for with the seasonal changes in India are associated very big changes in the strength of the upper currents; and it is an obvious hypothesis that when the change in the upper currents takes place with unusual vigour the seasonal rainfall will be abundant. The pilot-balloon observations hitherto made strongly support this hypothesis, and what appears to hold in India very probably holds over a far wider region. Moreover, the idea that upper-air conditions are vital to the study of world weather derives support from the table of relationships with the Nile. The significant relationbe definitely estimated by comparing the indications that would have been given by it if employed during the past 19 years with the actual rainfall. Now the coefficient expressing the closeness of fit between the results of the formula and past data in 1908 was $0 \cdot 58$, and I should have been satisfied under the conditions if the indications of the past 19 years had a closeness of fit of 0.48 instead of 0.58 ; actually, however, as will be seen from Fig. 4, the foundations of the relationship have proved sound and the coefficient has worked out as 0.56 ; so it may be claimed that our present improved formulæ based on 50 or 55 years instead of 35 years are worthy of confidence if used with due caution. It is in my view essential that forecasts should only be issued when the indications are well marked, and if during the past 19 years a prediction had only been made in the 11 years when an excess or deficit of one inch or more had been indicated, the character of the season's rainfall, expressed merely as ' in excess ' or 'in defect,' would have been correctly given 9 times (Fig. 4).

Since 1908 many new relationships have been ascertained, and the present formulæ for NorthWest India and for the Peninsula have coefficients ships with other stations for its single season number 31 , while the greatest number for a single season at any other centre is 24; and as the corresponding number for pressure at Cairo is only 8, it seems likely that this effect of the Abyssinian rainfall is brought about by the agency of the upper air, not by surface conditions. Similarly,

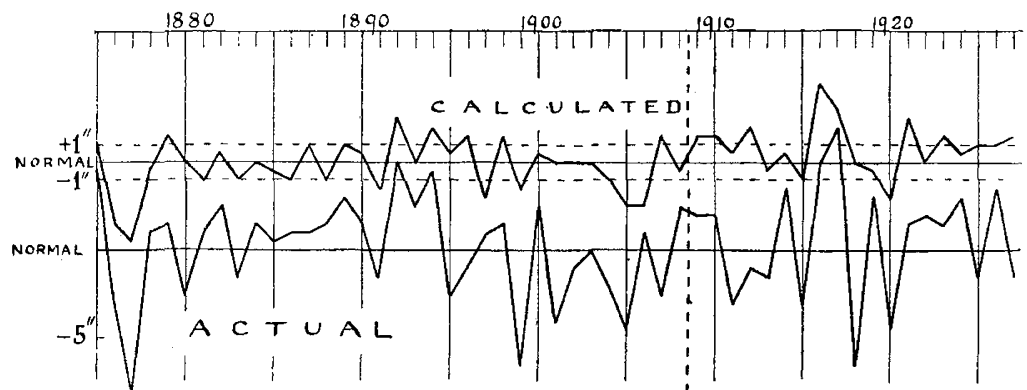

FIG. 4.-Forecast on June 1 of Indian monsoon, June-September. (1908 Formula, $R=0 \cdot 58$.) the monsoon rainfall of India has eight significant relationships elsewhere, but June to August pressure in North-West India only one.

It is to be hoped, therefore, that the tables of the Réseau Mondial, to which statistical workers have been enormously indebted in the past, will in future contain monthly means of air motion at fixed heights above such observatories as can provide the data.

\title{
Recent Earthquakes in Bulgaria and Greece.
}

\section{By Dr. Charles Davison.}

W ITHIN the last year, destructive earthquakes have occurred in Palestine, the Crimea, Smyrna, and Asia Minor, and, so lately as Mar. 27, in north-eastern Italy. They have been followed, during the latter half of April, by a series of equally violent shocks in the south-east of Europe. Indeed, the close succession of earthquakes-and, since April 15, scarcely a day has passed without news of fresh shocks-has given rise to the impression that earthquakes have of late been more frequent than usual. There is

No. 3053, Vor. 121]

nothing to support the impression beyond the clustering of shocks within a limited area. Assigning roughly the intensity according to Milne's scale for destructive shocks, it would seem that, in the first four months of this year, there have been one earthquake of intensity III (strong enough to destroy towns and devastate wide regions), perhaps two of intensity II (capable of shattering many buildings and overthrowing some), and two of intermediate strength. In each of ten years during the latter half of the nineteenth century there 
have, during the first four months, been from three to five earthquakes of intensity III, and in each of thirteen years from three to nine earthquakes of intensity II.

The earthquakes of April 14 and 18 are described as the most violent ever felt in Bulgaria, and this is not improbable. There is a centre of some importance near Plovdiv (Philippopolis), and there are a few minor centres to the south of the Balkans, but, in the area first struck, earthquakes are exceedingly rare, if not unknown. - The earthquake of April 14 occurred at about 11 A.M., and it is to this no doubt that we owe the small death-roll. The area of damage is about 70 miles long from east to west (Harmanli to Plovdiv) and 25 miles wide. The epicentre lies near Chirpan, probably a few miles to the south and close to Borisovgrade, which is almost entirely destroyed. The second great earthquake came on April 18 at 9.24 P.M., again at a time when most of the inhabitants were able to escape from the falling houses. The shock was distinctly stronger than the first and the area of damage was somewhat larger. Near Papazli, the distortion of the ground is evident; ground-levels have been changed in some places by so much as six feet, whether by crushing of the surface soil or by distortion of the underlying crust is as yet unknown. In both earthquakes the wide extent of the area of damage seems to point to a considerable depth of focus.

By far the most interesting feature of the Bulgarian earthquakes is the great and rapid oscillation of the focus. The epicentre of the earthquake of April 18 was close to Papazli, about half-way between Chirpan and Plovdiv and 10 miles to the west of the first epicentre. On the evening of April 19 it was displaced to Haskovo, 30 miles to the east of Papazli ; two days later, on April 21, it had retraced its steps about 60 miles to the west, to near Golemokonare; on April 23, back 36 miles to the east, to Stara Zagora, a few miles north of Chirpan; and, lastly, on April 26, it continued its easterly march, by 24 miles farther, to the neighbourhood of Harmanli.

According to the official reports, only 103 persons were killed and 700 wounded by these earthquakes, while the total loss of property is estimated at $3 \frac{3}{4}$ million pounds. In Plovdiv alone, more than five thousand houses have been damaged and twothirds of the town rendered uninhabitable.

Very different from the Bulgarian earthquakes were those felt at and near Corinth on April 22 and following days. In the first place, they visited one of the most seismically active countries in the world. Area for area, there are more than three times as many earthquakes, weak and strong, in Greece as in Japan, and more than thirty times as many as in Italy. Or, counting only shocks of the very highest intensity, there are more than four times as many as in Italy, and nearly seven times as many as in Japan. Again, in this active country, the isthmus of Corinth is one of the most active regions, being exceeded, according to Montessus, only by the Ionian Islands to the west of Greece and, though very slightly, by the island of Euboea to the east. In the third place, the area of destruction is small. It includes Corinth itself, in which many of the houses are damaged, the small adjoining towns of Kalamaki and Loutraki, and some of the coast villages to the west of Corinth. At the most, it may be about 10 miles in diameter, for it appears that Isthmia, four miles to the east, escaped injury during the first shock. The small area of damage, and the high intensity near its centre, combine in pointing to a shallow-seated focus. Lastly, though the foci of the after-shocks were not stationary, the limits of migration were small. On April 25 there seems to have been a slight shift to the east, most of the houses in Isthmia being destroyed.

So far as our present information goes, the Corinthian earthquakes were less important than those in Bulgaria, and owed their destructive power chiefly to the proximity of the origin to the surface.

\section{The Voronoff Operation in Stock-breeding.}

$\mathrm{T}$ HE claims made by Dr. Voronoff and others concerning the economic value of his method of reactivation in the field of practical livestock breeding have attracted so much public interest that it was considered desirable that an authoritative report should be prepared for the information of the Ministry of Agriculture and for the Board of Agriculture for Scotland. Delegates from Great Britain, with representatives of several other countries, recently visited Algeria to witness the operation of testis-grafting in animals of agricultural importance, to examine certain animals which already had been subjected to this technique, and to examine and to report upon the claims that have been made concerning the economic value of its application. Their report has now been issued. ${ }^{1}$

1 Ministry of Agriculture and Fisheries: Board of Agriculture for Scotland. Report on Dr. Serge Voronoff's Experiments on the Improvement of Livestock. By Dr. F. H. A. Marshall, Dr. F. A. E. Crew, Dr. A. Walton, and Wm. C. Miller. Pp. 24. (London: H.M. Stationery Office, 1928.) $9 d$. net
The Voronoff operation has been employed in the case of the senile male whose own testes have become insufficient in their physiological activity, and of the sexually immature male whose testes have not yet profoundly affected the developing characterisation of the individual. It is claimed that in the first case the old, decrepit and infecund male becomes reactivated, his reproductive powers becoming restored; and that in the second, growth and general vigour are stimulated to a fuller expression as evidenced by the attainment of a larger body size and a greater sexual potency. It is also claimed that these characters are, in part at least, transmitted to the offspring. The delegates were shown a bull which had been rejuvenated, and a number of sheep in which the operation had been performed upon the sexually immature male.

The conclusions at which the delegates arrived were as follows: The claim of Dr. Voronoff to effect rejuvenation of the aged and decrepit animal

No. 3053, VoL. 121] 